\title{
Sporicidal activity of mixtures of alcohol and hypochlorite
}

\author{
D. COATES AND JANET E. DEATH \\ From the Disinfection Reference Laboratory, Central Public Health Laboratory, Colindale Avenue, London $\vec{O}$ \\ NW95HT, UK
}

SUMMARY In an investigation of the activity against Bacillus subtilis spores of various mixtures of alcohol and sodium hypochlorite $50 \%$ methanol with enough hypochlorite to provide 2000 parts $\vec{\sim}$ per million available chlorine in distilled water was the most sporicidal. This mixture, both when $\vec{A}$ freshly prepared and for at least eight hours after mixing, achieved a five-log reduction in spore $\stackrel{\infty}{\infty}$

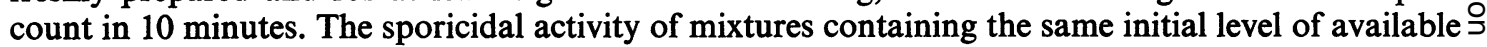
chlorine was found to vary with the alcohol, initial alcohol concentration, and age of the mixture. $\vec{T}$ Such mixtures may be useful for disinfecting heat-sensitive instruments.

Kelsey et al. (1974) investigated the sporicidal activity of hospital disinfectants. Freshly prepared mixtures of methanol and hypochlorite were far more sporicidal than any proprietary products they tested. They suggested a contact time of 15 minutes with a freshly prepared solution containing $50 \%$ methanol and enough sodium hypochlorite to provide 2000 parts per million available chlorine (ppm av. $\mathrm{Cl}$ ) in distilled water for disinfecting clean, heat-sensitive instruments except those of plated metal. The length of time that the mixture retained activity was not reported. We measured the sporicidal activity of various mixtures of alcohol and hypochlorite when freshly prepared and for up to 24 hours after mixing. The available chlorine in the mixtures was chemically assayed in parallel with the sporicidal studies to see whether sporicidal activity was proportional to the amount of available chlorine.

\section{Material and methods}

The alcohols used were methanol (AnalaR), propan-1-ol (AnalaR) and propan-2-ol (AnalaR) (Hopkin and Willians Ltd), ethanol (absolute) (James Burrough Ltd), and ethanediol (SLR) (Fisons Ltd). The hypochlorite used was sodium hypochlorite solution $(10 \%-14 \% \mathrm{w} / \mathrm{v}$ available chlorine) (BDH Ltd). Sterile distilled water was used as diluent. Bacillus subtilis, NCTC 10073, spores were used in the sporicidal studies. Kelsey et al. (1974) had tested spores of two Bacillus spp and

Received for publication 11 August 1977 two Clostridium spp against methanol and hypo-chlorite mixtures and found those of $B$. subtilis most $\vec{\varphi}$ resistant. An aqueous suspension of $B$. subtilis spores ${ }^{\circ}$ was prepared by the method of Beeby and Whitehouse (1965) and stored at $4^{\circ} \mathrm{C}$. Resistance to heat $\sum_{3}$ and sodium hypochlorite were tested periodically; no changes were detected over the experimental period.

Tests were carried out in a water bath thermostatically controlled at $25^{\circ} \pm 0.1^{\circ} \mathrm{C}$ and equipped $\frac{\circ}{3}$ with an immersible magnetic stirrer. Reagents were pipetted into universal bottles and placed in the water bath to equilibrate. After 30 minutes a test mixture (15 $\mathrm{ml}$ volume) of alcohol and hypochlorite? was prepared in another universal bottle (containing a $\frac{5}{3}$ magnetic stirrer bar) clamped in position over the immersible magnetic stirrer. The mixtures tested $O$ contained alcohol concentrations ranging from $10 \%$ to $50 \%$ and an available chlorine level of $2000 \mathrm{ppm}$ 윽 av. $\mathrm{Cl}$.

After mixing alcohol and hypochlorite the inoculum was added immediately when studying the $N$ sporicidal activity of fresh mixtures and after a time-lapse of up to 24 hours when studying the $N$ activity of ageing mixtures: $0.04 \mathrm{ml}$ spore suspension $\mathrm{N}^{\mathrm{N}}$ was added, which gave about $10^{7}$ spores $/ \mathrm{ml}$ of test 0 mixture. At timed intervals up to 60 minutes after 0 adding inoculum $1-\mathrm{ml}$ samples were taken and $\widetilde{\varnothing}$ added to $9 \mathrm{ml}$ of an $0.5 \%$ aqueous solution of sodium $\stackrel{\odot}{-}$ thiosulphate. Several possible inactivators were 0 tested by the method proposed in British Standard $\stackrel{\circ}{\circ}$ 3286 (1960). Both $0.5 \%$ sodium thiosulphate in $\stackrel{D}{\Omega}$ distilled water and nutrient broth proved suitable $\stackrel{\mathbb{Q}}{\mathbb{\perp}}$ 
for the mixtures of alcohol and hypochlorite under test. Thiosulphate was selected because it is chemically defined. Tenfold dilutions of sample/inactivator were made in 1/4 strength Ringer's solution when necessary. Viable counts were performed by the Miles and Misra (1938) method using nutrient agar plates incubated at $32^{\circ} \mathrm{C}$ for seven days. With low survival levels the membrane filtration technique was adopted.

The available chlorine in freshly prepared and ageing mixtures was assayed by a sodium arsenite titration method (Coates, 1977). The pH of test mixtures was measured with a Philips PW9418 pH meter fitted with separate glass and reference electrodes. The latter had a movable ground-glass sleeve to provide a large liquid junction.

\section{Results}

\section{SPORICIDAL STUDIES}

No sporicidal activity was shown by $50 \%$ aqueous solutions of the alcohols over 24 hours. Sodium hypochlorite $2000 \mathrm{ppm}$ av. $\mathrm{Cl}$ effected two-log reductions in spore count in about 40 minutes. Adding alcohol to hypochlorite potentiated sporicidal activity (Fig. 1).

The alcohol/hypochlorite mixtures tested and the minimum $\log$ reductions in viable spore count achieved in a 15-minute exposure period are shown in Table 1. Two patterns of sporicidal activity were found over the eight-hour period after mixing. With ethanol, propan-1-ol, and propan-2-ol sporicidal activity was high initially but decreased as the mixture aged. Conversely, with methanol $(15 \%)$ and ethanediol sporicidal activity was low initially but increased as the mixture aged. In only one case was significant sporicidal activity found in 24-hourold mixtures. A mixture of $50 \%$ methanol and $2000 \mathrm{ppm}$ av. $\mathrm{Cl}$ achieved a five-log reduction when freshly prepared and for at least eight hours after preparation. The performance of $25 \%$ methanol and $2000 \mathrm{ppm}$ av. $\mathrm{Cl}$ was almost as good. Mixtures of $25 \%$ propan-1-ol and hypochlorite, $15 \%$ propan-1-ol and hypochlorite, and 20\% propan-2-ol and hypochlorite achieved five-log reductions when freshly prepared and for at least three hours after preparation. Sporicidal activity then decreased rapidly: less than one-log reduction was achieved six hours after preparation.

Table 2 shows the minimum log reductions in viable spore count achieved by the most effective mixtures in different contact times. A mixture of $50 \%$ methanol and $2000 \mathrm{ppm}$ av. $\mathrm{Cl}$ achieved a five-log reduction in 10 minutes when freshly prepared and for at least eight hours after mixing. A mixture of $25 \%$ methanol and $2000 \mathrm{ppm}$ av. $\mathrm{Cl}$ showed relatively little sporicidal activity in 10 minutes when freshly prepared, but activity increased to a significant level within two to three hours. A mixture of $15 \%$ propan-2-ol and 2000 ppm av. $\mathrm{Cl}$ mixture achieved a five-log reduction in 30 minutes when freshly prepared and for at least four hours after mixing, but activity then diminished. A similar reduction was achieved by a mixture of $15 \%$ propan-1-ol and $2000 \mathrm{ppm}$ av. $\mathrm{Cl}$, but with 60 minutes' contact.

\section{CHEMICAL STUDIES}

Adding alcohol to hypochlorite effected a progressive loss of available chlorine with time. The rate at which available chlorine was lost varied with $(a)$ the initial concentration of alcohol, $(b)$ the alcohol used, and $(c)$ the initial hypochlorite concentration.

Table 3 shows the rates of loss of available chlorine in mixtures of $15 \%, 25 \%$, and $50 \%$ methanol and $2000 \mathrm{ppm}$ av. Cl. The greater the alcohol concentration the quicker was the rate of loss of available chlorine. Similar results were obtained with each of

Table 1 Minimum log reductions in viable count of B. subtilis spores achieved by mixtures of alcohol and hypochlorite in 15 minutes

\begin{tabular}{|c|c|c|c|c|c|c|c|c|c|}
\hline \multicolumn{2}{|l|}{ Mixture } & \multicolumn{8}{|c|}{ Age of mixture (hours) } \\
\hline Alcohol & ppmav. $\mathrm{Cl}$ & Fresh & 1 & 2 & 3 & 4 & 6 & 8 & 24 \\
\hline $\begin{array}{l}50 \% \text { Methanol } \\
25 \% \text { Methanol } \\
15 \% \text { Methanol }\end{array}$ & $\begin{array}{l}2000 \\
2000 \\
2000\end{array}$ & $\begin{array}{r}5 \\
5 \\
<1\end{array}$ & $\begin{array}{r}5 \\
4 \\
<1\end{array}$ & $\begin{array}{l}5 \\
4 \\
1\end{array}$ & $\begin{array}{l}5 \\
5 \\
1\end{array}$ & $\begin{array}{l}5 \\
5 \\
1\end{array}$ & $\begin{array}{l}5 \\
5 \\
5\end{array}$ & $\begin{array}{l}5 \\
5 \\
5\end{array}$ & $\begin{array}{l}<1 \\
<1 \\
<1\end{array}$ \\
\hline $\begin{array}{l}25 \% \text { Ethanol } \\
15 \% \text { Ethanol }\end{array}$ & $\begin{array}{l}2000 \\
2000\end{array}$ & $\begin{array}{l}4 \\
5\end{array}$ & $\begin{array}{l}4 \\
4\end{array}$ & 3 & $\begin{array}{r}<1 \\
4\end{array}$ & 4 & $\begin{array}{l}<1 \\
<1\end{array}$ & & $<1$ \\
\hline $\begin{array}{l}25 \% \text { Propan-1-ol } \\
15 \% \text { Propan-1-ol }\end{array}$ & $\begin{array}{l}2000 \\
2000\end{array}$ & $\begin{array}{l}5 \\
5\end{array}$ & $\begin{array}{l}5 \\
5\end{array}$ & $\begin{array}{l}5 \\
5\end{array}$ & $\begin{array}{l}5 \\
5\end{array}$ & $\begin{array}{l}3 \\
3\end{array}$ & $\begin{array}{l}<1 \\
<1\end{array}$ & $\begin{array}{l}<1 \\
<1\end{array}$ & $\begin{array}{l}<1 \\
<1\end{array}$ \\
\hline $\begin{array}{l}25 \% \text { Propan-2-ol } \\
20 \% \text { Propan-2-ol } \\
15 \% \text { Propan-2-ol } \\
10 \% \text { Propan-2-ol }\end{array}$ & $\begin{array}{l}2000 \\
2000 \\
2000 \\
2000\end{array}$ & $\begin{array}{l}5 \\
5 \\
4 \\
3\end{array}$ & $\begin{array}{l}5 \\
5 \\
4 \\
2\end{array}$ & $\begin{array}{l}5 \\
5 \\
4\end{array}$ & $\begin{array}{l}2 \\
5 \\
4 \\
3\end{array}$ & $\begin{array}{l}4 \\
3\end{array}$ & $\begin{array}{r}<1 \\
<1 \\
3 \\
3\end{array}$ & $\begin{array}{r}< \\
2\end{array}$ & $\begin{array}{r}<1 \\
<1 \\
<1 \\
\quad 2\end{array}$ \\
\hline $\begin{array}{l}25 \% \text { Ethanediol } \\
15 \% \text { Ethanediol }\end{array}$ & $\begin{array}{l}2000 \\
2000\end{array}$ & $\begin{array}{l}<1 \\
<1\end{array}$ & $\begin{array}{l}4 \\
1\end{array}$ & $\begin{array}{l}5 \\
5\end{array}$ & $\begin{array}{l}5 \\
5\end{array}$ & $\begin{array}{l}5 \\
5\end{array}$ & $\begin{array}{l}1 \\
5\end{array}$ & $<1$ & $\begin{array}{l}<1 \\
<1\end{array}$ \\
\hline
\end{tabular}


Table 2 Minimum log reductions in viable count of B. subtilis spores achieved by selected mixtures of alcohol and hypochlorite

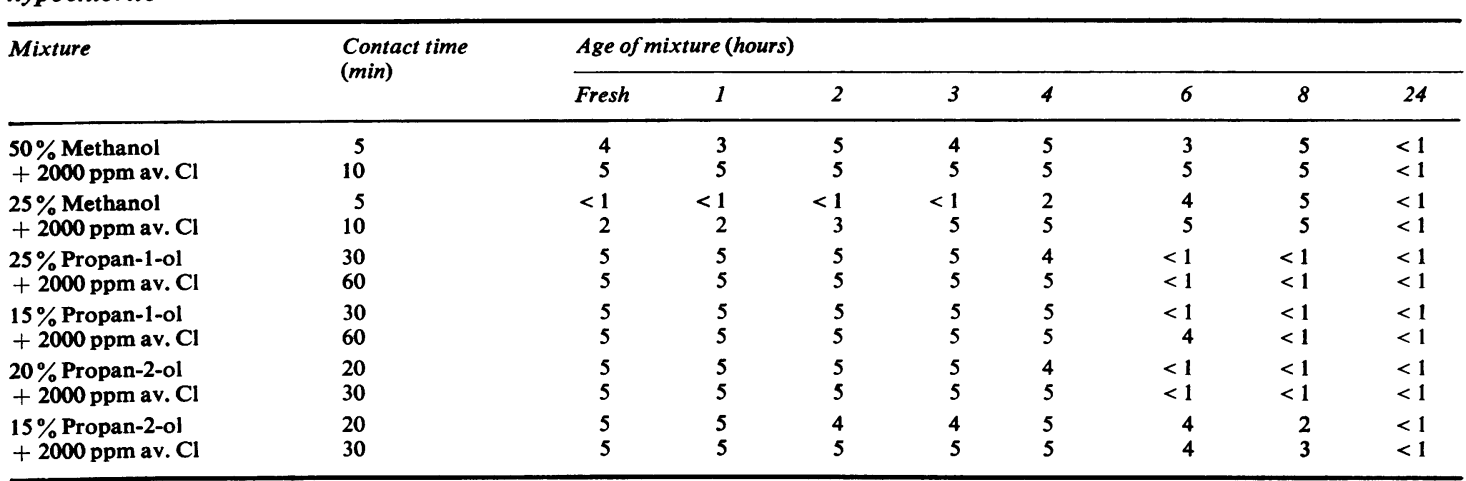

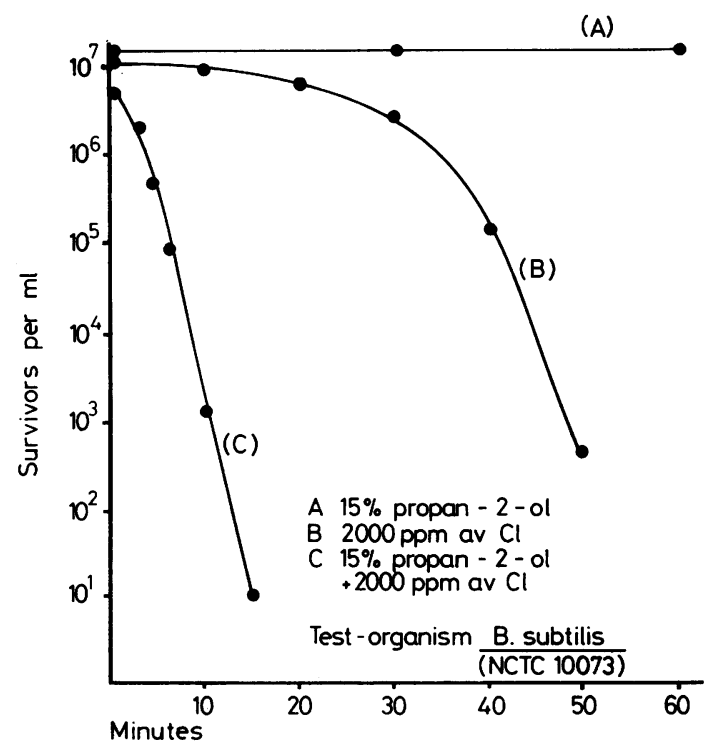

Fig. 1 Sporicidal activity of propan-2-ol, sodium hypochlorite, and mixtures of propan-2-ol and hypochlorite.

the five alcohols. Table 3 also shows the rates of loss of available chlorine in five different mixtures of $25 \%$ alcohol and $2000 \mathrm{ppm}$ av. $\mathrm{Cl}$. The rate of loss of available chlorine varied with the alcohol used.

Figure 2 shows the effect of the initial hypochlorite concentration on the rate of loss of available chlorine in mixtures of $25 \%$ ethanol and hypochlorite. A similar set of curves was obtained with each alcohol. The greater the initial concentration of hypochlorite the quicker was the overall rate of loss of available chlorine. At low remaining levels of available chlorine the curves either crossed (as with $25 \%$ ethanol mixtures) or merged. In control experiments there was no measurable loss of available chlorine in aqueous hypochlorite solutions.

With mixtures of ethanol and hypochlorite, $\vec{T}$ propan-1-ol and hypochlorite, and propan-2-ol and $\mathbb{D}$ hypochlorite sporicidal activity decreased as available chlorine levels decreased and no significant sporidical activity remained after all the available chlorine was lost. With methanol and ethanediol, however, sporicidal activity increased as available chlorine levels decreased. With mixtures of $50 \%$ methanol and $2000 \mathrm{ppm}$ av. $\mathrm{Cl}$ all available chlorine was lost in two hours (Table 3). Sporicidal activity, however, remained very high for at least eight hours (Table 2). Thus, in the mixtures of alcohol and

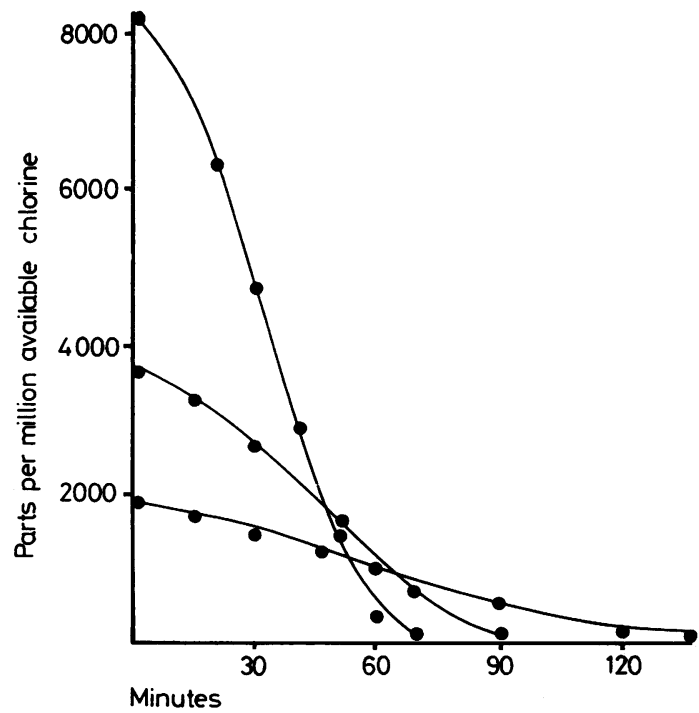

Fig. 2 Effect of initial hypochlorite concentration on rate of loss of available chlorine in mixtures of $25 \%$ ethanol and hypochlorite. 
hypochlorite studied no general relationship was found between the level of available chlorine present and sporicidal activity.

As the mixtures aged the $\mathrm{pH}$ changed (Table 4). Two patterns were found. In mixtures containing ethanol or propan-2-ol a slight rise in $\mathrm{pH}$ occurred as the level of available chlorine fell (Table 3). However, in mixtures containing methanol, propan1-ol, or ethanediol the $\mathrm{pH}$ dropped considerably as the level of available chlorine fell. The reductions varied with the alcohol and alcohol concentration.

Table 3 Loss of available chlorine with age of mixtures

\begin{tabular}{lrrrrrrrr}
\hline $\begin{array}{l}\text { Alcohol }+2000 \\
\text { ppm av. } C l\end{array}$ & \multicolumn{1}{l}{ ppmav. $C l$} \\
\cline { 2 - 8 } & Fresh & $I h$ & $2 h$ & $4 h$ & $6 h$ & $8 h$ & $24 h$ \\
\hline $15 \%$ Methanol & 1980 & 1550 & 1260 & 1100 & 800 & 250 & 0 \\
$25 \%$ Methanol & 1980 & 780 & 400 & 15 & 10 & 0 & 0 \\
$50 \%$ Methanol & 1980 & 15 & 0 & 0 & 0 & 0 & 0 \\
$25 \%$ Ethanol & 1980 & 990 & 350 & 0 & 0 & 0 & 0 \\
$25 \%$ Propan-1-ol & 1980 & 1190 & 700 & 40 & 0 & 0 & 0 \\
$25 \%$ Propan-2-ol & 1980 & 1050 & 320 & 10 & 0 & 0 & 0 \\
$25 \%$ Ethanediol & 1980 & 1400 & 900 & 390 & 130 & 80 & 0 \\
& & & & & & & & \\
\hline
\end{tabular}

Table 4 Changes in $\mathrm{pH}$ with age of mixtures

\begin{tabular}{|c|c|c|c|c|c|c|c|}
\hline \multirow{2}{*}{$\begin{array}{l}\text { Alcohol }+2000 \\
\text { ppm av. Cl }\end{array}$} & \multicolumn{7}{|l|}{$p H$} \\
\hline & Fresh & $I h$ & $2 h$ & $4 h$ & $6 h$ & $8 h$ & $24 h$ \\
\hline $\begin{array}{l}15 \% \text { Methanol } \\
25 \% \text { Methanol } \\
50 \% \text { Methanol } \\
25 \% \text { Ethanol } \\
25 \% \text { Propan-1-ol } \\
25 \% \text { Propan-2-ol } \\
25 \% \text { Ethanediol }\end{array}$ & $\begin{array}{l}11 \cdot 1 \\
11 \cdot 2 \\
11 \cdot 4 \\
11 \cdot 5 \\
11 \cdot 6 \\
11 \cdot 7 \\
10.8\end{array}$ & $\begin{array}{r}11 \cdot 0 \\
10 \cdot 4 \\
8 \cdot 9 \\
12 \cdot 0 \\
11 \cdot 3 \\
12 \cdot 1 \\
9 \cdot 8\end{array}$ & $\begin{array}{r}10 \cdot 7 \\
9 \cdot 5 \\
8 \cdot 0 \\
12 \cdot 2 \\
11 \cdot 0 \\
12 \cdot 3 \\
9 \cdot 0\end{array}$ & $\begin{array}{r}10 \cdot 0 \\
7 \cdot 0 \\
7 \cdot 7 \\
12 \cdot 2 \\
10 \cdot 6 \\
12 \cdot 3 \\
8 \cdot 1\end{array}$ & $\begin{array}{r}9 \cdot 4 \\
7 \cdot 0 \\
7 \cdot 7 \\
12 \cdot 2 \\
10 \cdot 0 \\
12 \cdot 3 \\
6 \cdot 0\end{array}$ & $\begin{array}{r}8 \cdot 5 \\
7 \cdot 0 \\
7 \cdot 6 \\
12 \cdot 2 \\
9 \cdot 8 \\
12 \cdot 3 \\
5 \cdot 4\end{array}$ & $\begin{array}{r}6 \cdot 0 \\
7 \cdot 0 \\
7 \cdot 6 \\
12 \cdot 2 \\
8 \cdot 4 \\
12 \cdot 2 \\
4 \cdot 8\end{array}$ \\
\hline
\end{tabular}

\section{Discussion}

There is a need for a liquid chemical sterilant that works quickly at room temperature. Autoclaves may not be available or the items to be sterilised may be thermolabile. Costly instruments such as endoscopes may have to be used more than once during an operating session and a 15-minute turnround time between patients rules out ethylene oxide or low temperature steam and formaldehyde cycles. Contaminated surfaces may need to be sterilised.

Because bacterial spores are relatively difficult to kill it is usually assumed that a process which kills all spores present also kills all other microbial forms present-that is, it sterilises. Most liquid chemical disinfectants, however, have little or no sporicidal action. Formalin is slowly sporicidal at room temperature but its use is limited by its pungent odour, which severely irritates mucous membranes. A $2 \%$ activated solution of glutaraldehyde (available commercially as Cidex) is claimed to kill all spores in three hours, but Kelsey et al. (1974) found it to be a poor sporicide in three hours except when freshly activated. Concentrated hypochlorite solutions are sporicidal at room temperature but unfortunately are very corrosive. This apparent lack of an ideal liquid chemical sterilant led us to continue the research started by Kelsey et al. (1974) on the sporicidal activity of mixtures of alcohol and hypochlorite.

Our results with $B$. subtilis spores confirm that a mixture of $50 \%$ methanol and $2000 \mathrm{ppm}$ av. $\mathrm{Cl}$ is highly sporicidal. It achieves a five-log reduction in viable spore count in 10 minutes when freshly prepared and for at least eight hours after mixing. A mixture of $25 \%$ methanol and $2000 \mathrm{ppm}$ av. $\mathrm{Cl}$ is also highly sporicidal, achieving almost a five-log reduction in viable spore count in 15 minutes when freshly prepared and for at least eight hours after mixing. The other mixtures are not so good. When sporicidal activity is as high it does not last so long. It may be that different results would be obtained with spores of other test organisms.

We do not know why mixtures of alcohol and hypochlorite are so highly sporicidal. The alcohol, which alone has no sporicidal activity, may 'soften' the spore coat facilitating penetration by hypochlorite ion, hypochlorous acid, and, possibly, an alcoholhypochlorite reaction product. Sporicidal activity cannot be directly correlated with available chlorine. With mixtures of alcohol and hypochlorite containing ethanol, propan-1-ol, or propan-2-ol sporicidal activity decreases as available chlorine diminishes. However, with mixtures containing methanol or ethanediol the opposite occurs. In mixtures containing ethanol or propan-2-ol the $\mathrm{pH}$ increases as available chlorine diminishes. However, with mixtures containing methanol, propan-1-ol, or ethanediol the $\mathrm{pH}$ decreases.

Hence, different mechanisms seem to be involved. The microbiocidal activity of available chlorine is greatly affected by pH (Sykes, 1967). At a high pH (pH 11 and above) almost all available chlorine is present in the form of hypochlorite ion, which is relatively inactive. As $\mathrm{pH}$ decreases available chlorine progressively takes the undissociated, uncharged form of hypochlorous acid, which is extremely active. Hence chemical reactions between alcohols and hypochlorite that result in a decrease in $\mathrm{pH}$ may effect increased microbiocidal activity. Certainly as mixtures containing methanol or ethanediol age $\mathrm{pH}$ decreases and sporicidal activity increases, whereas with mixtures containing ethanol or propan-2-ol pH increases and sporicidal activity decreases. However, with propan-1-ol mixtures pH decreases with age and sporicidal activity decreases. Hence pH is not the only factor involved. 
We recognise certain practical snags with the mixtures investigated. The alcohol and hypochlorite components must be dispensed separately. Alcohol is a solvent. Hypochlorite is corrosive and seriously inactivated by organic matter.

In other experiments we have shown that the sporicidal activity of mixtures is greatly increased by buffering to a lower $\mathrm{pH}$. In this way it is possible to devise mixtures containing much lower concentrations of alcohol and hypochlorite that are just as sporicidal. This study will be reported in another paper.

\section{References}

Beeby, M. M., and Whitehouse, C. E. (1965). A bacterial spore test piece for the control of ethylene oxide sterilization. Journal of Applied Bacteriology, 28, 349-360.

British Standards Institution (1960). Method for Laboratory Evaluation of Disinfectant Activity of Quaternary Ammonium Compounds (BS. 3286). British Standards Institution, London.

Coates, D. (1977). Kelsey-Sykes capacity test: origin, evolution and current status. Pharmaceutical Journal, 219, 402-403.

Kelsey, J. C., MacKinnon, I. H., and Maurer, I. M. (1974). Sporicidal activity of hospital disinfectants. Journal of Clinical Pathology, 27, 632-638.

Miles, A. A., and Misra, S. S. (1938). The estimation of the bactericidal power of the blood. Journal of Hygiene, 38, 732-749.

Sykes, G. (1967). Disinfection and Sterilization, 2nd edition, pp. 381-400. Spon, London. 